\title{
Study of the Hardness and Microstructure of Quenched ABNT 1045 Steel Bars and Their Relationship to the Lumped Thermal Systems
}

\author{
Luiz Gustavo Barbosa*, Luciano Goetems, Carlos Alexandre Rech, Fábio Luis Knewitz \\ Instituto Federal de Educação, Ciência e Tecnologia do Rio Grande do Sul - Campus Erechim, Erechim, Brazil
}

\begin{abstract}
Lumped thermal systems are characterized by uniform interior temperature during heat transfer processes, having as only important factor the time. Thus, the present research has proposed to investigate one of these systems in order to determine a maximum radius along which the microstructure and hardness are homogeneous after performing a quenching heat treatment. Cylindrical samples with diameters equal to 12.7, 14.0, 15.0, 16.0, 16.5, 17.0, 18.0 and 19.0 mm of ABNT 1045 steel were produced with ratios of $20: 1$ between the length and radius. Afterwards, they were heated in a kiln to $845^{\circ} \mathrm{C}$, where they remained between 30 minutes (smaller diameter) and 45 minutes (larger diameter), for complete austenitization. Thereafter, they were rapidly cooled in water to room temperature. With the samples already sectioned, the hardness values were measured and the microstructures along the radius were verified by metallography. The results indicated that for the samples of 12.7, 14.0 and $15.0 \mathrm{~mm}$, the hardness measurements were the same in the center, in the middle of the radius and near the surface, characterizing martensitic microstructures that were corroborated by the metallographies. For the samples of $16.0,16.5,17.0,18.0$ and $19.0 \mathrm{~mm}$, the results were not homogeneous along the radius. In this way, it has been found that the maximum diameter at which ABNT 1045 steel cylindrical bars behave as lumped thermal systems is $15.0 \mathrm{~mm}$.
\end{abstract}

Keywords Lumped thermal systems, Quench, Hardness, Microstructure, ABNT 1045 Steel

\section{Introduction}

In heat transfer analysis, some pieces are observed to behave like a "lump" whose interior temperature remains essentially uniform at all times during a heat transfer process. The temperature of such bodies can be a function of time only. Heat transfer analysis that utilizes this idealization is known as lumped system analysis, which provides great simplification in certain classes of heat transfer problems without much sacrifice from accuracy [1]. Thus, the lumped thermal systems allow enormous convenience in heat transfer analysis, simplifying the resolution of several problems because the number of variables involved in the process is reduced, since, in most cases, the temperature of the bodies varies with the time and position $[1,2]$.

However, not every pieces can be considered this kind of system when submit to heat exchanges. A geometry must be defined relating the diameter and length of the piece, so that the thermal conductivity can be considered infinite $[1,2]$.

* Corresponding author:

luiz.barbosa@erechim.ifrs.edu.br (Luiz Gustavo Barbosa)

Published online at http://journal.sapub.org/ijmee

Copyright $@ 2019$ The Author(s). Published by Scientific \& Academic Publishing

This work is licensed under the Creative Commons Attribution International

License (CC BY). http://creativecommons.org/licenses/by/4.0/
When the diameter or thickness of a sample is low, the heat conduction occurs such that the temperature difference between the end and the center in the course of the heat transfer process is negligible [1]. In a quench heat treatment, in wich the temperature gradient along the specimen radius or width can be neglected, the specimen temperature can be considered depending only time interval [2]. This assertion can be applied to pieces that have the smallest radius in relation to length, characterizing lumped thermal systems.

Thus, if the temperature of a lumped thermal system is homogeneous all through the radial extent, it is assumed that throughout the sample the microstructure and hardness will be the same after quenching. The aim of this research was to study an infinite length cylinders, samples in which the transformations occurred homogeneously along its radial extension during a quenching, determining a maximum radius for this occurrence in the treated material.

The experimental verification of this idea would simplify the choice of materials and diameters for the production of components that require homogeneous properties from the surface to the center. As an example, when a piece requires homogeneous hardness throughout its length, it is sufficient to perform quenching in a piece that behaves as a lumped thermal system.

Bergman et al. [2] mention that the lumped thermal systems have their internal temperature varying only with 
Luiz Gustavo Barbosa et al.: Study of the Hardness and Microstructure of Quenched ABNT 1045 Steel Bars and Their Relationship to the Lumped Thermal Systems

time. Thus, an analogy to heat treatments performed can be made if a sample of carbon steel has characteristics that resemble this kind of system. Therefore, when a piece that was subjected to a heat treatment exhibits the same properties and microstructures throughout its cross-section, is possible claim that heat transfer rate in quenching was the same all through the radial extent [3].

The formation of martensite in the quenching process originates only with the shear of the structure, there being no atomic diffusion, presenting the same composition of the origin phase [4]. Its formation begins when a certain temperature is reached and increases proportionally to the decrease of this one, ceasing the transformation in a point where the temperature and the quantity of carbon do not allow more the formation of martensite [5]. Thus, when performing quenching in a lumped thermal system, the martensite formation must be homogeneous throughout its entire cross-section [3].

According Callister [6] the chemical composition of the pieces influences the characteristics of the thermal systems. The addition of alloying elements in a steel, for example, changes its thermal conductivity and modifies the Biot number. Therefore, the study should be carried out with samples of similar chemical compositions in order to avoid discrepancies in the results.

Hasan et al. [7] carried out studies on cylindrical samples produced with steels of different chemical compositions, which were cooled in water. These samples had $52 \mathrm{~mm}$ diameters and a diminutive radius with relation to the length. In this study was verified that the samples presented homogeneous microstructures throughout the volume. Even when the microstructure of the samples was not totally martensitic, other phases such as ferrite and retained austenite were present throughout the piece, thus guaranteeing the homogeneity of the temperature variation of the samples during quenching. In the same way, Oliveira et. al. [8] obtained homogenous martensitic structures when quenched cylindrical test specimens made of SAE $4140 \mathrm{H}$ steel of $50.8 \mathrm{~mm}$ diameter in water cooling medium. Hemig et. al. [9] compare the hardness results along the radius of $42 \mathrm{CrMo}$ steel samples cooled in water with mathematical simulations of the volumetric fraction and the hardness of the constituent martensite formed after cooling. Both results show the martensite formation along the radius of the $20 \mathrm{~mm}$ diameter sample. Again, the presence of alloying elements such as silicon, manganese, chromium and molybdenum allowed the specimens to behave like lumped thermal systems, despite the diameters.

Therefore, in this study, tried to verify the occurrence or not of a gradient temperature between the surface and the center of the samples during the cooling. Such verification was carried out by means of hardness tests, once the cooling rates during quenching and the resulting hardness are directly related, and by means of metallographies along the samples radius. Thus, the samples that showed similar hardness and microstrutures along the radius, was considered "lumped thermal systems". But, is very important to cite that, in our case, the ABNT 1045 carbon steel without alloying elements, difficultly will present complete martensitic transformation after quenching of thick pieces.

\section{Materials and Methods}

Cylindrical samples were made in ABNT 1045 carbon steel, with diameters equal to $12.7,14.0,15.0,16.0,16.5$, $17.0,18.0$ and $19 \mathrm{~mm}$ with a ratio of $20: 1$ between the length and radius. Also, test specimens of ABNT 1045 steel were prepared for the Jominy test according to ASTM 255-10. The samples were individually heated to $845^{\circ} \mathrm{C}$ and remained in the furnace between thirty minutes (smaller diameter) and forty five minutes (larger diameter) for complete austenitization. Afterwards, were quenching in water with manual agitation and later sectioned in half the length, to obtain surfaces (samples) for metallographic analysis and hardness tests.

To perform the hardness tests of this work was used the ASTM E18-00 standard that governs the Rockwell hardness tests, and limits the distance that must exist between the indentations and among these and the edge of the analyzed surface. For each quenched bar, four sectioned samples were separated for the hardness tests, and in each sample a hardness value was obtained for the center. Already, for half of the radius and near the surface it was possible to perform four indentations on the surface of the samples, being they to the right, to the left, above and below the center, thus allowing a greater number of results for each sample. Figure 1 illustrates the locations where indentations were performed. The hardness test was performed in the Rockwell $\mathrm{C}$ scale with an equipment of the TIME TH301 brand, located in the Laboratory of Mechanical Testing of the IFRS - Campus Erechim.

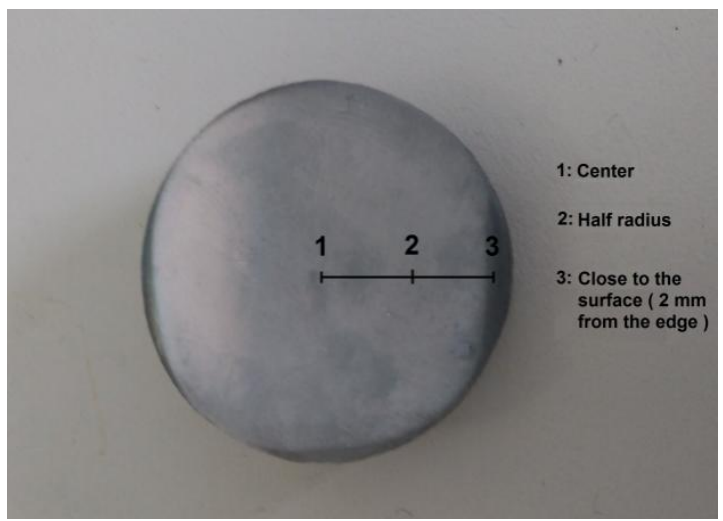

Figure 1. Points under which the indentations necessary to obtain the hardness results were performed

The samples that were not destined to the hardness tests were submitted to metallographic tests in order to verify the microstructural homogeneity along the radius. By optical microscope, were obtained images in the center, in half of the radius and close to the surface, according to Figure 2, to perform a continuous analysis of the microstructures along the radius of the samples. 


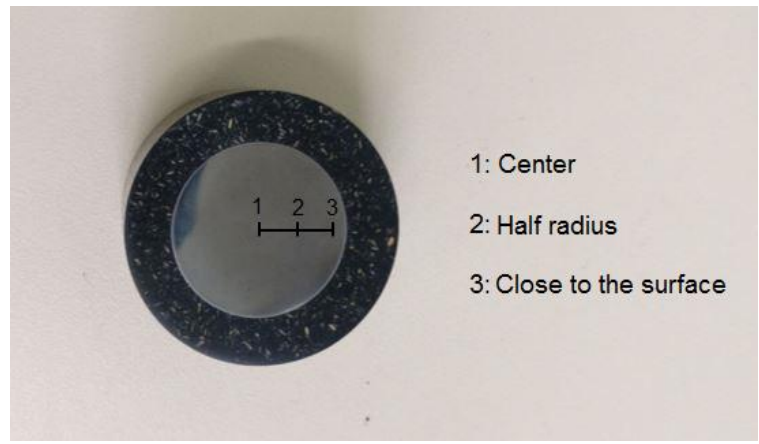

Figure 2. Points under which metallography was performed along the radius of the samples

The Jominy test was perform with the aim of analyzing the hardness of ABNT 1045 steel and comparing the hardness results obtained with samples quenched by immersion in water. This test followed ASTM A255-10.

\section{Results and Discussions}

It can be observed, according to the graph of Figure 3, that the samples with a diameters of 12.7, 14.0, 15.0, 16.0 and $16.5 \mathrm{~mm}$ indicated hardness values consistent with those normally presented in martensitic steels throughout the radial extension, proving the total hardening after cooling. In the other samples is possible to verify no homogenous hardening throughout the radial extent, since the results of hardness obtained close to surface are compatible with martensitic microstructures, unlike the values collected in the center, which no present high hardness. So, is possible to verify that in the bars with diameter of 17.0, 18.0 and $19 \mathrm{~mm}$ the cooling rates were not the same along the radial extension. However, analyzing the standard deviation, is possible to infer that the hardness is the same along the radial extension for the samples with diameters of 12.7, 14.0 and $15 \mathrm{~mm}$. Its leads us to believe that the cooling rates along the radius are also the same only for these samples. So, we conclude that the $15 \mathrm{~mm}$ bar is the largest diameter that presented same results of hardness at the analyzed points, corresponding to matensitic microstruture.

It can be seen that the microstructures shown in Figure 4a are predominantly martensitic along the radius, and match the hardness values presented in Figure 3. In the same way, in Figure $4 \mathrm{~b}$, the predominant microstructure is martensite, but with lower incidence, because this was the maximum radius that presented same cooling rate in the three points analyzed of the samples. Finally, with the micrographs presented in Figures $4 \mathrm{c}$ it is possible to identify different microstructures along the radius, where the martensite formation occurred only near the surface, unlike the center that present bainitic microstructures. These micrographs corroborate with the hardness values shown in Figure 3. Combining the values of hardness and micrographs is possible to verify that the cylindrical bar of steel ABNT 1045 with larger diameter that did not present a significant temperature gradient during the cooling was of $15 \mathrm{~mm}$. With this is possible to affirm that the cooling rate was practically the same in the surface and inside the bar, for the samples with diameters of $15 \mathrm{~mm}$ and below these. Such samples, that in the center and close to the surface presented the austenite transformed in martensite after quenching, can be treated how "lumped thermal systems".

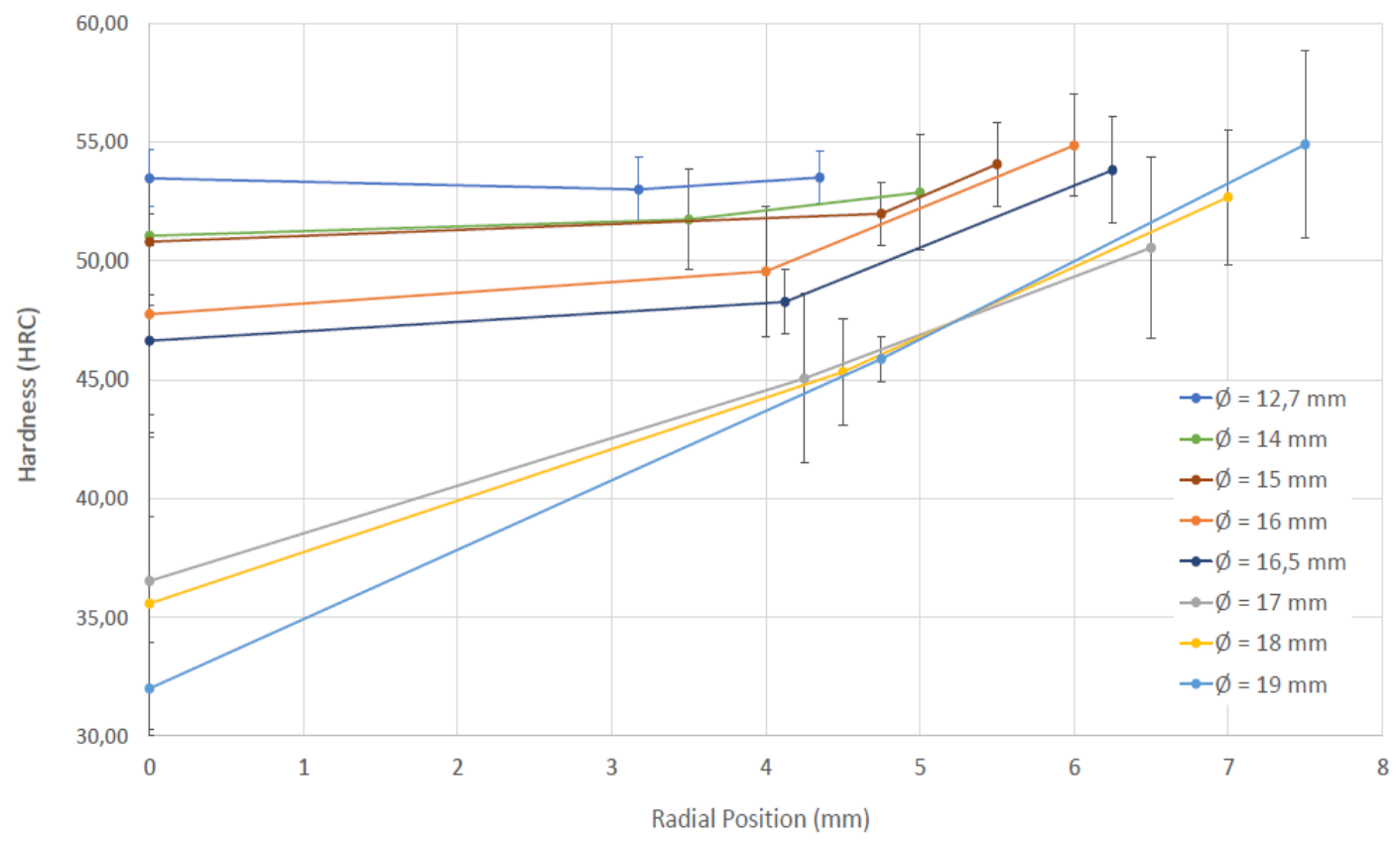

Figure 3. Mean of the hardness values as a function of the position analyzed 


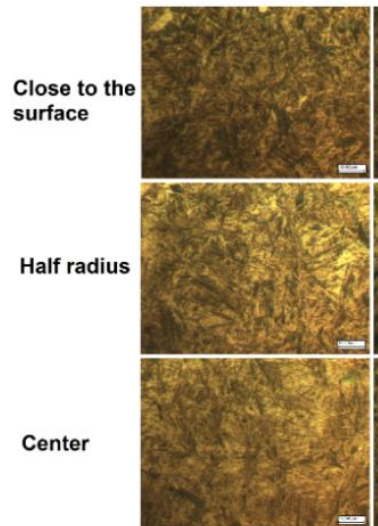

(a)

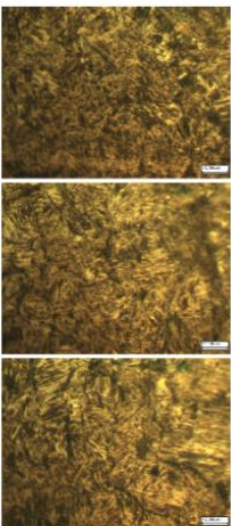

(b)

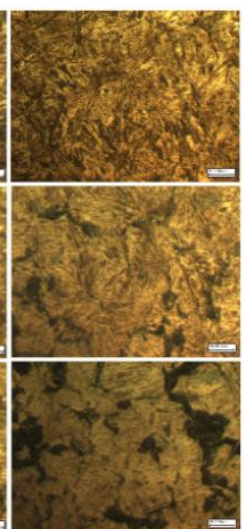

(c)
Figure 4. Micrographs of quenched bars of (a) $12.7 \mathrm{~mm}$, (b) $15 \mathrm{~mm}$ and (c) $19 \mathrm{~mm}$ diameter, organized according to the analysis position. 1000X magnification

To perform the Jominy test, two specimens were prepared in order to compare the hardness depth in this cooling method with the method in which the bars were totally immersed in water. The graph in Figure 5 show the hardness with respect to the distance of the border cooled of the specimens tested, that indicates the hardness was $52 \mathrm{HRC}$ close to the border cooled, that matches with a martensitic microstructure extending until approximately the position $3.2 \mathrm{~mm}$. After, there is a sudden drop, where at $4.8 \mathrm{~mm}$ from the border cooled the hardness is $30 \mathrm{HRC}$, corresponding of bainitic or pearlitic microstructure. Still, at more longer distances from the border cooled, the hardness found is very low, near $10 \mathrm{HRC}$, characterizing perlite and even ferritic microstructures.

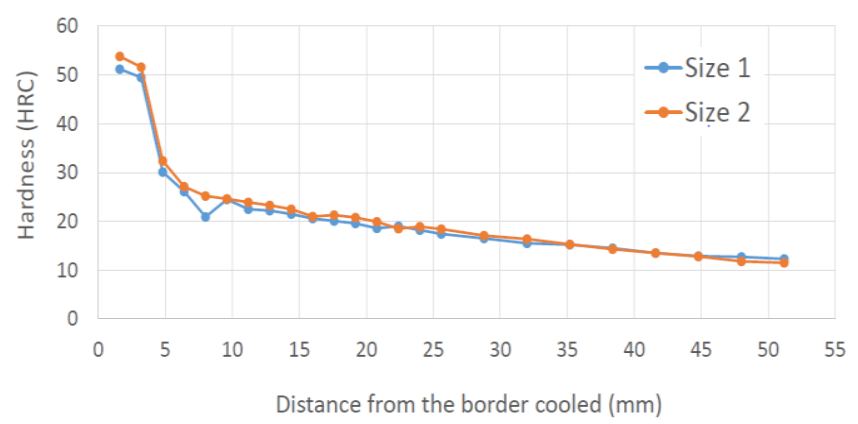

Figure 5. Curve of hardness with respect to the distance from the border cooled of ABNT 1045 steel after Jominy test

\section{Conclusions}

From the results it was possible to conclude that the maximum diameter at which ABNT 1045 carbon steel cylindrical bars behave as lumped thermal systems was 15 $\mathrm{mm}$. For these samples, along of radius, the hardness values is practically the same in the center, in the half of the radius and near the surface and, the predominant microstructure is martensite. So, the bars with diameters of 12.7, 14.0 and 15.0 $\mathrm{mm}$ must have a similar values for the cooling rates in the surfaces and in the centers. However, the bars with diameters of 17.0, 18.0 and $19 \mathrm{~mm}$, was found that the surface cooling rate was higher than the center, justified by the hardness values obtained in these regions. The micrographs obtained in these samples corroborate with the results of hardness found, since near the surface the microstructure is martensitic, unlike half of the radius and the center, which present bainitic microstructures.

It was still possible to verify that in the bars of 16 and 16.5 $\mathrm{mm}$ in diameter, both the hardness and the micrographs, indicated a martensitic microstructure but with different cooling rates.

Finally, comparing the Jominy test of the border cooled with the cooling method in which the cylindrical bars were totally immersed in water, it is possible to affirm that the cooling rate was higher in the latter. In this method the samples were hardened homogenously up to $7.5 \mathrm{~mm}$ radius from the cooled end, two times greater than the hardened distance in the Jominy test.

\section{ACKNOWLEDGEMENTS}

We would like to thanks Professor Demian Boaroli for his attention and assistence with the material used in this research. Also, Professor Luciano Aparecido Kempski, as well as the laboratory technicians Artur and Emerson, for the support in the samples preparation.

\section{REFERENCES}

[1] ÇENGEL, Yunus A.; GHAJAR, Afshin J. Transferência de Calor e Massa: Uma Abordagem Prática. Adaptação Mehmet Kanoglu. Tradução Fátima A. R. Lino. 4. ed. Porto Alegre: AMGH, 2012.

[2] BERGMAN, Theodore L. et al. Condução Transiente. In: BERGMAN, Theodore L. et al. Fundamentos de Transferência de Calor e de Massa. 7. ed. Rio de Janeiro: Ltc, 2014. Cap. 5. p. 180-182.

[3] STACHELSKI, L. B. ESTUDO DA MICROESTRUTURA OBTIDA EM BARRAS DE AÇO-CARBONO TEMPERADAS E SUA RELAÇÃO COM OS SISTEMAS TÉRMICOS AGLOMERADOS. 2016. 97 f. Monografia Curso de Engenharia Mecânica, Instituto Federal de Educação Ciência e Tecnologia do Rio Grande do Sul, Erechim, 2016.

[4] NUNURA, César Rolando Nunura. Correlação Numérico-experimental da Microestrutura, Taxa de Resfriamento e Características Mecânicas do Aço ABNT 1045. 2009. 124 f. Dissertação (Mestrado) - Curso de Engenharia Mecânica, Departamento de Engenharia Metalurgica, Universidade Federal do Rio Grande do Sul, Porto Alegre, 2009.

[5] CHIAVERINI, Vicente. Aços e Ferros Fundidos. São Paulo: Associação Brasileira de Metalurgia, Materiais e Mineração, 2012. 
[6] CALLISTER, William D. Materials Science and Engineering: An Introduction. 7. ed. Rio de Janeiro: Ltc, 2008. 705 p.

[7] HASAN, H. S. et al. Heat Transfer Coefficients during Quenching of Steels. [s.L.]: University Of Cambridge, 2011. $14 \mathrm{p}$.

[8] OLIVEIRA, W. P., SAVI, M. A., PACHECO, P. M. C. L., SOUZA, L. F. G. Thermomechanical analysis of steel cylinders quenching using a constitutive model with diffusional and non-diffusional phase transformations. Mechanics Of Materials, [s.1.], v. 42, n. 1, p.31-43, jan.2010. ElsevierBV.
[9] HEMING, C., JIANG, F., HONGGANG, W. Estimation of the mechanical properties of a $42 \mathrm{CrMo}$ steel cylinder with phase transformation during quenching. Journal of Materials Processing Technology, 63 (1997), pp. 568-572. 